\title{
PATOLOGIA DAS CONSTRUÇÕES: ESTUDO DE CASO EM UMA INSTITUIÇÃO DE ENSINO SUPERIOR DE FORTALEZA-CE
}

\author{
Alencar, Marília C. A. M. \\ Engenheira Civil \\ Centro Universitário Christus \\ Ceará; Brasil \\ marilia_carla10@hotmail.com \\ Andrade, Paula N. \\ Professor \\ Centro Universitário Christus \\ Ceará; Brasil \\ paulanobreandrade@gmail.com
}

\author{
Bezerra, Eric M. F. \\ Professor \\ Centro Universitário Christus \\ Ceará; Brasil \\ eric_mateusjes@hotmail.com \\ Nobrega, Agerbon C. C. \\ Professor \\ Centro Universitário Christus \\ Ceará; Brasil \\ nobrega2017@yahoo.com
}

\section{RESUMO}

O aparecimento de manifestações patológicas possuem efeitos comprovadamente danosos ao desempenho das edificações. Para sanar as avarias, é necessário identificar, a partir de determinados padrões apresentados, a causa do dano e conhecer as técnicas de recuperação disponíveis para definir a que melhor se adequada à situação analisada. Existe, portanto, a necessidade da realização de estudos investigativos que considerem a análise técnica, de modo a ampliar o arcabouço de informações acerca da patologia das edificações. O presente trabalho tem como objetivo analisar as principais manifestações patológicas encontradas em uma instituição de ensino superior, diagnosticar possíveis causas e sugerir soluções de correção. Para tanto, será aplicada a metodologia GUT (gravidade, urgência e tendência). A instituição estudada possui um fluxo acentuado de pessoas, sendo sua preservação importante para seus frequentadores e para os usuários do meio no seu entorno.

Palavras-chave: manifestações patológicas, metodologia GUT, manutenção corretiva.

\section{ABSTRACT}

The appearance of pathological manifestations has proven to be harmful to the performance of buildings. To remedy the damage, it is necessary to identify, based on certain patterns presented, the cause of the damage and to know the recovery techniques available to define the one that best suits the situation analyzed. Therefore, there is a need to conduct investigative studies that consider technical analysis, in order to expand the information framework about the pathology of buildings. This paper aims to analyze the main pathological manifestations found in a higher education institution, diagnose possible causes and suggest corrective solutions. For this, the GUT methodology will be applied. The studied institution has an accentuated flow of people, its preservation being important for its regulars and users of the environment in its surroundings.

Keywords: pathological manifestations, GUT methodology, corrective maintenance.

\section{INTRODUÇÃO}

Em paralelo às melhorias na técnica e nos insumos da construção das edificações, houve, contraditoriamente, um aumento no número de problemas encontrados nas mesmas. Muito disso decorre da busca pela redução do custo e do tempo de execução das construções. A economia financeira obtida na construção, proveniente da utilização de materiais de baixa qualidade e de um corpo técnico desqualificado, poderá levar, doravente, a um custo superior ao que foi economizado.

As avarias eclodidas em uma edificação podem comprometer a devida utilização de um sistema específico, causar malestar aos usuários ou, em casos mais críticos, levar ao colapso da mesma. Devido aos danos catastróficos associados ao colapso de uma edificação, que vão desde a perda de bens materiais até o comprometimento da vida humana, há um 
inegável interesse social em evitar um sinistro em potencial de qualquer edificação, seja ela de domínio público ou privado.

A patologia das construções, com base na etimologia da palavra, trata, portanto, do estudo das doenças das edificações (deriva do grego phatos, que significa doença e logos, que significa estudo). Segundo Helene (2003), patologia é um conjunto de estudos dos sintomas, mecanismos, causas e as origens dos erros nas construções civis, isto é, o estudo do diagnóstico do problema.

A falta de manutenções preventivas faz com que a ação continuada dos agentes agressivos evolua as anomalias para problemas críticos. Além do risco à vida, os custos envolvidos na manutenção predial, quando acumulados ao longo do tempo, assumem proporções significativas quando comparados com os investimentos iniciais de construção. Embora interpretada como uma atividade secundária, a manutenção é essencial e inevitável, repercutindo de forma direta na vida útil da edificação e em seu desempenho global

No contexto atual do mercado da construção civil, há uma elevada demanda por profissionais capazes de prevenir o surgimento de anomalias e, quando necessário, atuar na identificação das manifestações patológias e na proposta de intervenções técnicas adequadas para seu reparo e recuperação. Isso tem estimulado o interesse de profissionais da área da construção civil e tem motivado o desenvolvimento de pesquisas, cursos e palestras sobre essa temática. Em Fortaleza-CE, a Lei de Inspeção Predial N 9913, de 16 de julho de 2012, que torna obrigatória a vistoria técnica, manutenção preventiva e periódicas da edificação e equipamentos públicos ou privativos no município de Fortaleza, acentuou o interesse por esse campo de atuação.

São recorrentes casos em que a falta de manutenção e reparo das edificações culminam no colapso das mesmas. Esse descaso se acentua em obras públicas, mesmo muitos destes sendo patrimônios com conotações históricas, políticas, sociais e econômicas. Recentes eventos pezarosos, como o desabamento do Edifício Andrea, em Fortaleza, reforçam o descaso com os quais os sinais prévios de mal funcionamento da edificação são tratados. A negligência dos usuários e a imperícia de profissionais da área geram uma combinação dramática com elevado potencial trágico.

Motivado pelo exposto, este trabalho tem como principal objetivo identificar as manifestações patológicas de uma instituição de ensino superior em Fortaleza-CE e discutir suas possíveis origem. A instituição estudada possui um fluxo acentuado de pessoas, sendo sua preservação, portanto, importante para seus frequentadores e para os usuários do seu entorno. Além disso, espera-se contribuir no ramo da Engenharia Diagnóstica, dada a importância do conhecimento das várias origens de problemas distintos da construção civil para que se possa cada vez mais padronizar esses problemas patológicos e solucioná-los mais rapidamente.

\section{ENGENHARIA DIAGNÓSTICA}

A patologia das construções se refere a um ramo da engenharia o qual se estuda as anomalias presentes em construções que comprometem o adequado desempenho das mesmas. Entede-se por desempenho, segundo Souza e Ripper (2009), como o comportamento em serviço de cada produto, ao decorrer de sua vida útil, e reflete a satisfação em relação ao trabalho desenvolvido nas etapas de formação, projeto, construção e manutenção.

Segundo Gomilde, Pujadas e Fagundes Neto (2006), a engenharia diagnóstica é o ramo que estuda o fenômeno das manifestações patológicas. Para garantir o desempenho, a durabilidade e a vida útil da edificação, são necessárias ferramentas diagnósticas periciais para identificação, constatação e resolução de problemas e patologias, ainda que a manutenção esteja em dia. Estas ferramentas diagnósticas são, por sua vez, representadas pelas vistorias, inspeções, auditorias, perícias e consultorias.

De acordo com a NBR 13752 (ABNT, 1996), para a constatação mediante exame circunstanciado e descrição minuciosa dos elementos que o constituem é necessário fazer uma vistoria. Já a inspeção requer algo além da averiguação do objeto visoriado, pois o fator analítico deve estar presente, em geral com foco na qualidade e segurança. É uma análise técnica de fato, condição ou direito relativo a uma edificação (GOMILDE; GULLO; FAGUNDES NETO, 2009).

Gomilde, Gullo e Fagundes Neto (2009) acrescenta que auditoria é o atestamento técnico de conformidade de um fato, condição ou direito relativo a uma edificação. O procedimento visa checar se a condição edilícia em questão está conforme, ou não, ao padrão estabelecido em contrato, norma técnica ou legislação. A perícia em edificação, por sua vez, é a determinação da origem, causa e mecanismo de ação de um fato, condição ou direito relativo a uma edificação. 
Já a consultoria é a prescrição técnica a respeito de um fato, condição ou direito relativo a uma edificação. É, portanto, a atividade do técnico especialista ou do perito com conhecimentos específicos em prescrever soluções e recomendações para anomalias construtivas, patologias de sistemas, falhas de manutenção e demais fatos incidentes relativos à edificação.

Helene (2003) salienta que os problemas patológicos normalmente apresentam uma manifestação externa característica. A partir dessas pode-se deduzir qual a natureza, a origem e os mecanismos dos fenômenos envolvidos, permitindo estimar as prováveis consequências. Normalmente esses sintomas podem ser classificados por um primeiro diagnóstico, a partir de observações visuais.

O comprometimento de alguma exigência da construção, seja de caráter funcional, mecânico ou estético, caracteriza a existência de uma manifestação patológica (ANDRADE; SILVA, 2005). Portanto, as avarias de uma edificação estão associadas ao inadequado desempenho desta. Nesse sentido o termo desempenho pode ser compreendido como o comportamento em serviço de determinado produto ao longo de sua vida útil (SOUZA; RIPPER, 1998).

Um elemento pode não estar necessariamente condenado e mesmo assim apresentar desempenho insatisfatório em algum momento de sua vida útil. A avaliação desta situação talvez seja o maior objetivo da patologia das construções, visto que este é o momento que é necessário a intervenção técnica, de forma que ainda seja possível recuperar a edificação, postergando sua vida útil (SOUZA; RIPPER, 1998).

No projeto dos sistemas de uma edificação deve ser tomado medidas que assegurem sua durabilidade. De acordo com a ISO 13823 (2008), durabilidade é a capacidade de uma estrutura ou de seus componentes de satisfazer, com dada manutenção planejada, os requisitos de desempenho do projeto, por um período específico de tempo sob influência das ações ambientais, ou como resultado do processo de envelhecimento natural. O conceito de durabilidade associa-se diretamente à vida útil. Refere-se às características dos materiais e/ou componentes, às condições de exposição e às condições de utilização impostas durante a vida útil da edificação.

Ressalta-se, porém, que toda atividade humana de transformação de matérias-primas em produtos, desde que os processos se repitam sob certas condições essenciais, pode ser monitorada através de um adequado controle de qualidade, evitando-se ou minimizando a possibilidade de ocorrência de falhas. Desta maneira, muitos dos problemas patológicos que ocorrem nas construções poderiam ser evitados através da implantação de Programas de Controle da Qualidade, não só dos produtos, mas também das técnicas e procedimentos da construção (ELDRIDGE, 1982).

Durabilidade não é uma propriedade intrínseca dos materiais, mas sim uma função relacionada com o desempenho dos mesmos sob determinadas condições ambientais. O envelhecimento destes resulta das alterações das propriedades mecânicas, físicas e químicas, tanto na superfície como no seu interior, em grande parte devida à agressividade do meio ambiente (MEHTA; MONTEIRO, 2008).

Segundo Do Carmo (2003), a resolução de um problema patológico envolve um conjunto complexo de procedimentos a serem cumpridos, havendo variações para cada caso. A prática profissional de análise destes problemas, no entanto, tem sido muitas vezes caracterizada pela falta de uma metodologia cientificamente reconhecida e comprovada, prevalecendo, em muitas situações, as rotinas pessoais fundamentadas na experiência.

Vale salientar que a identificação da origem do problema permite também discernir, para fins judiciais, quem cometeu a falha, com uma investigação minuciosa, já que na etapa da construção uma fase depende da outra. Assim, se o problema teve origem, na fase de projeto, o projetista falhou; quando a origem está na qualidade do material, o fabricante errou; se na etapa de execução, trata-se de falha na mão-de-obra e ou a fiscalização ou a construtora foram omissos; se na etapa de uso, a falha é da operação e manutenção (ARAÚJO, 2004).

Conforme pode ser visto no estudo de Helene (2003) (Figura 1), é nas etapas de projeto onde se dá origem a uma elevada percentagem das manifestações patológica. Em geral as falhas de planejamento ou de projeto são mais graves que as falhas de planejamento ou má execução. É sempre melhor investir mais tempo no detalhamento e estudo que, por falta de programação, tomar decisões apressadas ou adaptadas durante a execução (HELENE, 2003). 


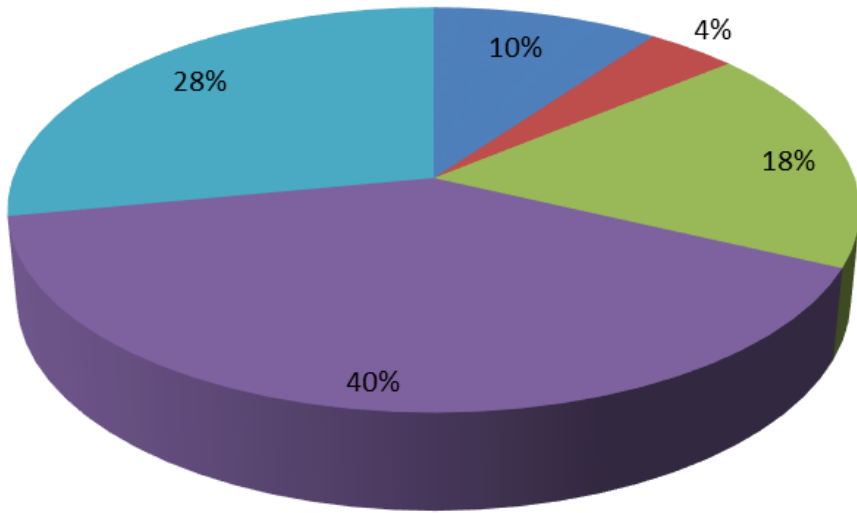

Uso

- Planejamento

Materiais

- Projeto

- Execução

Figura 1 - Origem dos problemas patológicos com relação as etapas de produção e uso das obras civis

Muitos desastres em edificações decorrem da ausência de manutenção. De acordo com a NBR 5674 (ABNT, 2012), entede-se por manutenção como o conjunto de atividades a serem realizadas ao longo da vida total da edificação para conservar ou recuperar a sua capacidade funcional e de seus sistemas constituintes de atender as necessidades e segurança dos seus usuários.

Addleson (1992) afirma que a manutenção preventiva é toda providência tomada com antecedência e previsão, durante o período de uso e manutenção da edificação. A mesma pode ser associada a um custo 4 (quatro) vezes menor que o necessário à correção dos problemas gerados a partir de uma intervenção não preventiva. Já a manutenção corretiva corresponde aos trabalhos de diagnostico, prognóstico, reparo e proteção das estruturas que já apresentam manifestações patológicas, ou seja, correção de problemas evidentes.

A inspeção predial, de acordo com o Instituto Brasileiro de Avaliações e Perícias de Engenharia de São Paulo (IBAPE/SP 2012), é ferramenta que propicia a avaliação sistêmica da edificação. Elaborada por profissionais habilitados e devidamente preparados, classifica não conformidades constatadas na edificação quanto a sua origem, grau de risco e indica orientações técnicas necessárias à melhoria da manutenção dos sistemas e elementos construtivos.

\section{METODOLOGIA}

O objeto de estudo trata-se de um prédio comercial e corporativo de três pavimentos que funciona como uma instituição de ensino superior, com 7.579,86 $\mathrm{m}^{2}$ de área construída, tendo sido construído em 1999 (Figura 1). A mesma foi concebida com estruturas em concreto armado, paredes de fechamentos em alvenarias de tijolo cerâmico, com fachadas parte revestida com cerâmica e parte com apenas reboco e pintura, esquadria metálica com vidro, circulações vertical feita através de escadas e rampas e circulação lateral por corredores, pisos em cerâmica e coberta parte em telha colonial e outra com telha metálica.

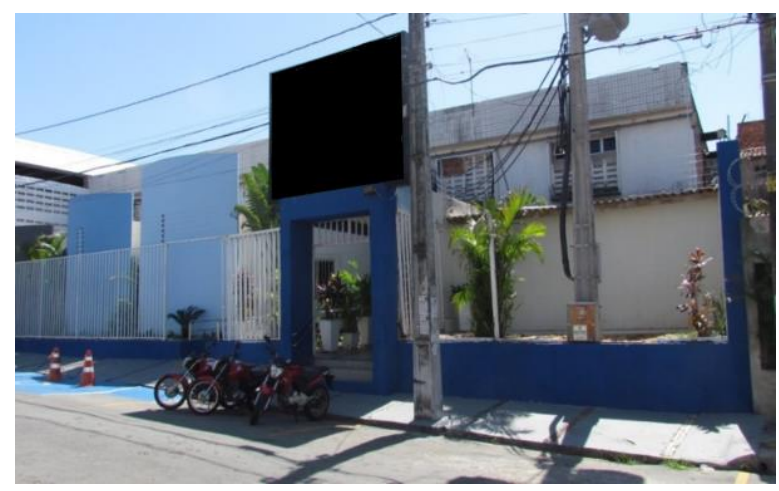

Figura 2 - Fachada da edificação analisada

A instituição conta com 9 Banheiros, Biblioteca, Copa, Cantina, Secretaria, Controle Acadêmico, Suporte tecnológico, TI, Arquivo, Almoxarifado, Depósito de água, 6 Salas de aula, 4 Laboratórios, Xerox, 4 Banheiros, CPA, Sala de estágio, Sala do diretor, Brinquedoteca, 2 Depósitos de materiais, Empresa Junior, 2 Auditórios, Sala de manutenção, Sala de reunião, 19 Salas de aula, 8 Salas de aula, 2 Banheiros. 
Foi realizada uma coleta dos dados das vistorias e uma análise do histórico da edificação com entrevistas das pessoas envolvidas e documentos comprobatórios, com intuito de obter informações sobre as técnicas construtivas adotadas e a periodicidade de manutenções corretivas e preventivas.

A fase inicial e documental se dá com a entrevista com o dono e responsável legal e levantamento preliminar de dados da edificação, visando ao cadastro de problemas já detectados e de níveis de expectativas dos usuários. Concomitantemente é feito o levantamento de documentação técnica, administrativa, de manutenção e legal da edificação.

Em seguida é feita a vistoria das áreas comuns da edificação com o levantamento fotográfico de todas as anomalias e/ou falhas existentes e aparentes da edificação, relacionadas a problemas de origem construtiva, uso, operação, manutenção, administrativas e legais. Será utilizada para análise das patologias um checklist da IBAPE (2017).

Foi utilizado o método GUT (Tabela 1) para ordenamento das prioridades das manifestações patológicas. De acordo com Knapp e Olivan (2015), esta ferramenta de gerenciamento de risco faz parte da teoria da decisão econômica, podendo, contudo, ser ajustada para uso em outras áreas, inclusive a engenharia civil.

Tabela 1 - Critérios do grau de risco e pesos referentes a metodologia utilizada para a classificação da ordem de prioridades das irregularidades

\begin{tabular}{c|c|c|c|c}
\hline Grau & Gravidade & Urgência & Tendência & Peso \\
\hline Altamente critico & $\begin{array}{c}\text { Perdas de vidas humanas, danos irreparáveis ao } \\
\text { meio ambiente ou perda do edifício }\end{array}$ & Evento em andamento & Evolução imediata & 5 \\
\hline Crítico & $\begin{array}{c}\text { Ferimento em pessoas, danos ao meioambiente } \\
\text { ou ao edifício }\end{array}$ & $\begin{array}{c}\text { Evento prestes a } \\
\text { ocorrer }\end{array}$ & $\begin{array}{c}\text { Evolução em curto } \\
\text { prazo }\end{array}$ & 4 \\
\hline Médio & $\begin{array}{c}\text { Desconforto, deterioração do meio ambiente ou } \\
\text { do edifício }\end{array}$ & $\begin{array}{c}\text { Evento prognosticado } \\
\text { para breve }\end{array}$ & $\begin{array}{c}\text { Evolução em } \\
\text { médio prazo }\end{array}$ & 3 \\
\hline Mínimo & Pequenos incômodos ou pequenos prejuízos \\
financeiros & $\begin{array}{c}\text { Evento prognosticado } \\
\text { para adiante }\end{array}$ & $\begin{array}{c}\text { Evolução em } \\
\text { longo prazo }\end{array}$ & 2 \\
\hline
\end{tabular}

Fonte: Gomide, Pujadas e Fagundes Neto (2009).

Após a classificação da manifestação de acordo com o grau, os pesos são multiplicados e com o resultado, usa-se os dados presentes na Tabela 2 para análise e avaliação das prioridades das manifestações.

Tabela 2 - Critérios do grau de risco e pesos referentes a metodologia utilizada para a classificação da ordem de prioridades das irregularidades

\begin{tabular}{c|c|c}
\hline Prioriadade & Pontuação & Prazo \\
\hline $1^{\circ}$ & 81 a 125 & Até 30 dias \\
\hline $2^{\circ}$ & 75 a 80 & 30 dias a 120 dias \\
\hline $3^{\circ}$ & 60 a 64 & 120 dias a 150 dias \\
\hline $4^{\circ}$ & 30 a 59 & 150 dias a 210 dias \\
\hline $5^{\circ}$ & 10 a 29 & 210 dias a 240 dias \\
\hline $6^{\circ}$ & 1 a 9 & 240 dias a 360 dias \\
\hline
\end{tabular}

Fonte: Gomide, Pujadas e Fagundes Neto (2009).

\section{RESULTADOS E DISCUSSÕES}

Para uma melhor apresentação dos resultados, as manifestações patológicas serão separadas e discutidas de acordo com os sistemas da edificação, que são: alvenarias de vedação, instalações hidrossanitárias, revestimentos, pinturas e estruturas de concreto. No grupo das estruturas de concreto, foram analisadas as lajes, vigas, pilares e escadas. Outros elementos, como, por exemplo, reservatório de concreto, tiveram seu acesso impossibilitado e, portanto, não fazem parte do escopo desse trabalho. 
Ao todo, foram identificadas 206 manifestações patológicas, divididas percentualmente entre os sistemas da edificação de acordo com o apresentado na Figura 3.

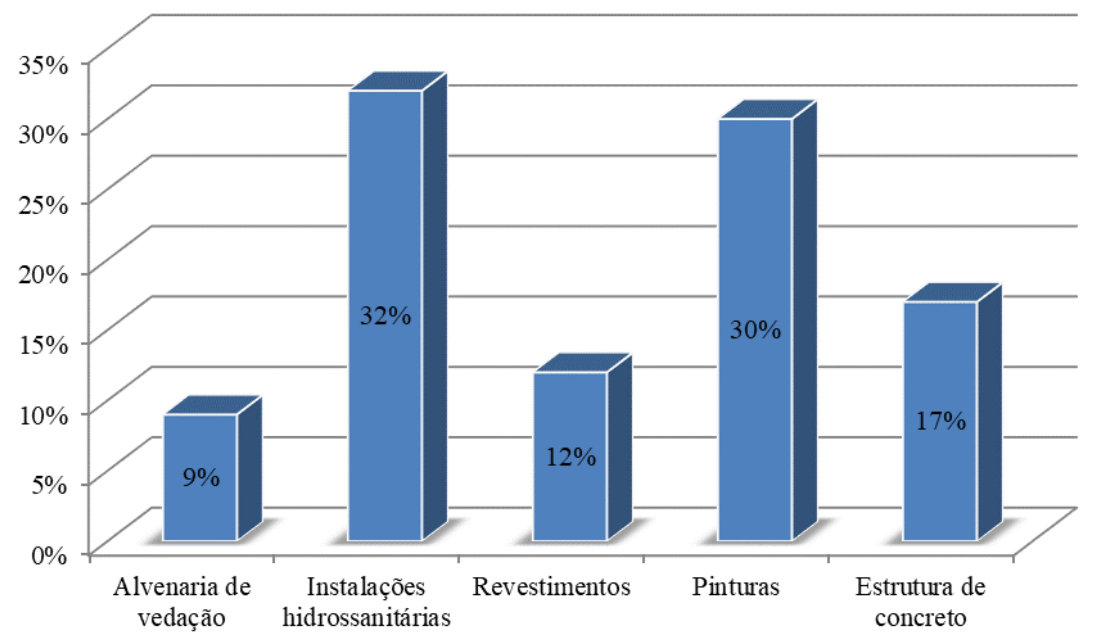

Figura 3 - Distribuições percentual das manifestações patológicas na edificação

\subsection{Alvenarias de vedação}

As alvenarias devem ser projetadas e construídas de modo a garantir a habitabilidade da edificação, apresentando características e propriedades, conforto térmico, estanqueidade, estabilidade, isolamento acústico e acabamento, transmitindo ao usuário a sensação de salubridade e bem-estar (DAL MOLIN, 1988).

Uma das principais manifestações patológicas nas alvenarias de vedação são as fissuras. Estas podem ser decorrentes da baixa resistência mecânica dos blocos ou da argamassa ou, ainda, por sobrecargas. A forma como a fissura irá se propagar indicará o motivo que levou ao seu surgimento. Thomaz (1989) salienta que as trincas são consideradas um dos avisos mais importantes dentre as manifestações patológicas, pois informa um possível colapso da estrutura.

$\mathrm{Na}$ edificação estudada, as fissuras nas alvenarias não comprometem o desempenho do sistema. Estas, no entanto, causam um dano estético que gera um desconforto nos usuários, tendo em vista que normalmente denotam sintomas mais graves. Nas paredes da escada de emergência, por exemplo, as fissuras apresentaram uma configuração característica de quando a resistência à tração do bloco de vedação é maior que a da argamassa utilizada (Figura 4).

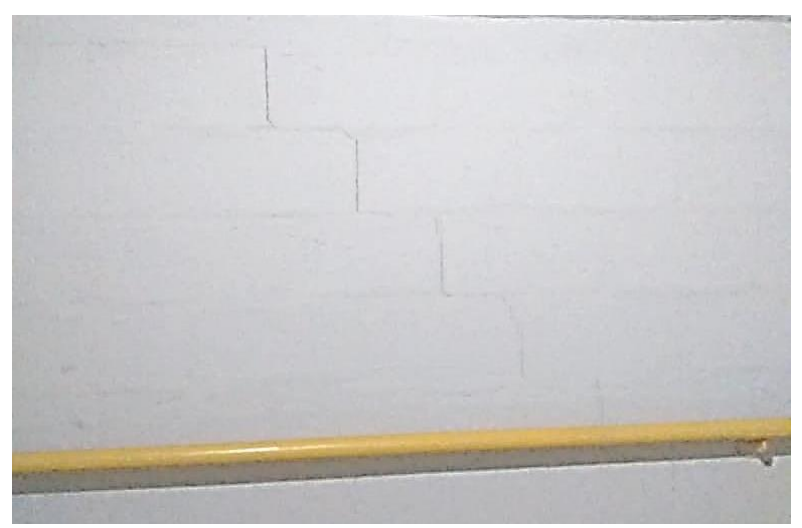

Figura 4 - Fachada da edificação analisada

De acordo com Caporrino (2018), se a causa foi instantânea e não teve uma continuidade, a solução é o reforço com tela na região fissurada; para realização de tal procedimento é necessário retirar todas as camadas de revestimento, chapiscar, fazer o emboço com a tela inserida e refazer os acabamentos. 
Multiplicando os valores estimados de gravidade, urgência e tendência das manifestações nas alvenarias (2, 3 e 2, respectivamente), obteve-se um resultado igual a 12, que resulta em uma prioridade 5 (210 dia a 240 dias para sanar a manifestação). Além do grau de prioridade, outro dado importante é que, das 19 manifestações patológicas encontradas nas alvenarias de vedação, $100 \%$ tiveram a classificação como anomalia da construção, ou seja, a manifestação ocorreu na etapa da obra, reforçando que neste sistema a manutenção não é a causa destas avarias.

\subsection{Instalações hidrossanitárias}

As instalações hidráulicas e sanitárias são constituidas pelos sistemas de água fria, água quente, esgotos e águas pluviais. O sistema predial hidrossanitário é um dos que entram em contato direto com o usuários e seu mau funcionamento é um indício da existência de patologias que resultam em queda do bem estar físico e psicológico das pessoas (VIEIRA, 2016).

Em seu estudo, Carvalho Júnior (2015) observou que das manifestações patológicas encontradas na contrução, cerca de $75 \%$ foram decorrentes de problemas relacionados com as instalações hidráulicas prediais. Vale destacar que em geral, de acordo com Teixeira et al (2011), manifestações patológicas frequentes nos sistemas hidrossanitários prediais não envolvem sérios riscos à vida ou à saúde dos seus usuários a curto prazo. Entretanto, Vieira (2016) salienta que essas falhas costumam causar transtornos e desconforto aos usuários, além do custo financeiro.

No estudo de caso, foi identificado que as maiores ocorrências de manifestações patológicas se deram no sistema de instalações hidrossanitárias (cerca de 32\%). Os defeitos encontrados foram os seguintes: vazamento da coluna de água fria devido à ruptura de tubulações; vazamento devido ao tensionamento nas tubulações de água fria; vazamento nos pontos de válvulas e registros; entupimento da rede de esgoto, devido à obstrução das tubulações; vazamento na rede de esgoto devido a ralos quebrados; problemas de recalque devido a não continuidade da tubulação de águas pluviais.

Na parte norte do empreendimento existe uma canalização de águas pluviais que não é contínua (Figura 5), fazendo com que a água da chuva coletada pelas tubulações sejam despejadas diretamente no solo. Com isso, há um represamento e formação de diversos cursos d'água correntes que convergem predominantemente para a base de alguns pilares, produzindo rapidamente acentuadas e progressivas erosões que podem levar a recalques diferenciais.

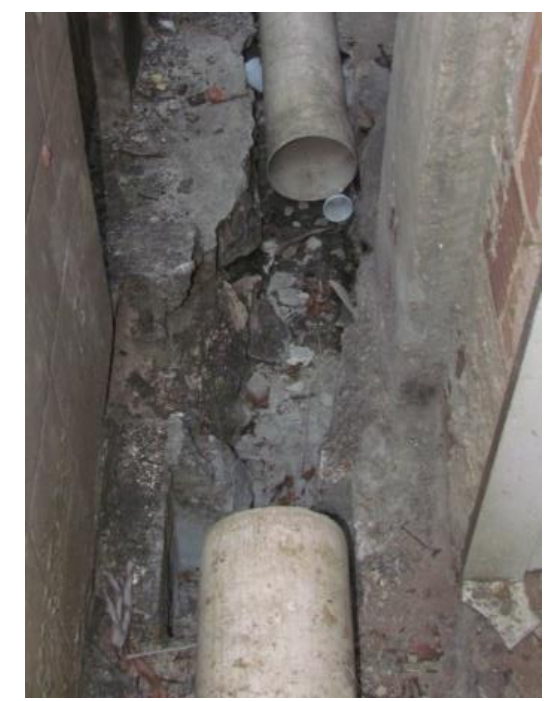

Figura 5 - Canalização de águas pluviais

De todos os ralos do empreendimento estudado, 65\% apresentam manifestações provenientes do entupimento da rede de esgoto devido à obstrução das tubulações. A classificação desta avaria se dá por falta de manutenção, pois não há registros de manutenção corretiva e também preventiva desses ralos. Para evitar esses problemas com entupimento de ralo, se faz necessário manter as manutenções periódicas e limpeza constante.

Foram identificadas infiltrações no revestimento decorrente do tensionamento na tubulação de instalações hidráulicas (Figura 6), pois as conexões foram colocadas desalinhadas da tubulação e, com isso, um esforço mecânico externo fez com que a canalização se rompesse e infiltrasse o revestimento. Essa avaria também afetou o revestimento. 


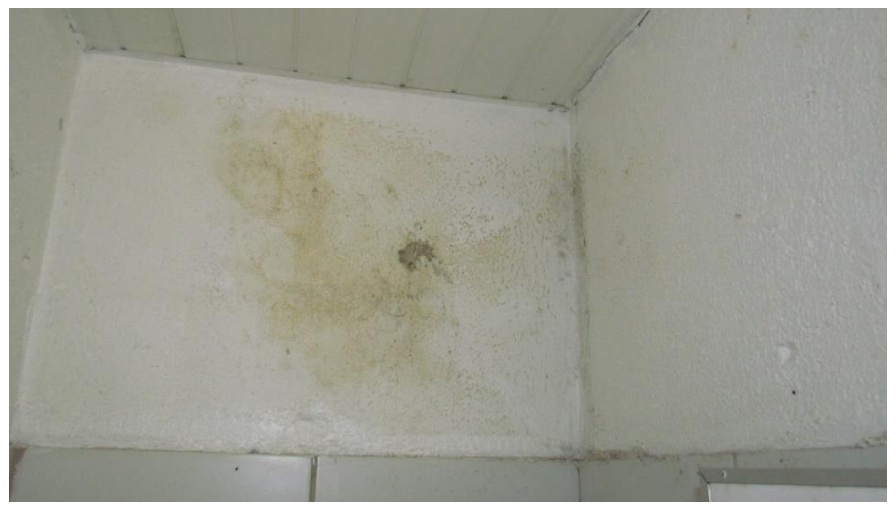

Figura 6 - Infiltração decorrente das instalações hidráulicas

Foi encontrado um vazamento na coluna de água fria, no shaft dos banheiros centrais, devido à ruptura de tubulações, como mostrado na Figura 7. A provável causa é o impacto que normalmente ocorre na etapa da obra que pode acontecer devido ao transporte e manuseio inadequado dos materiais, ou durante a ultilização.

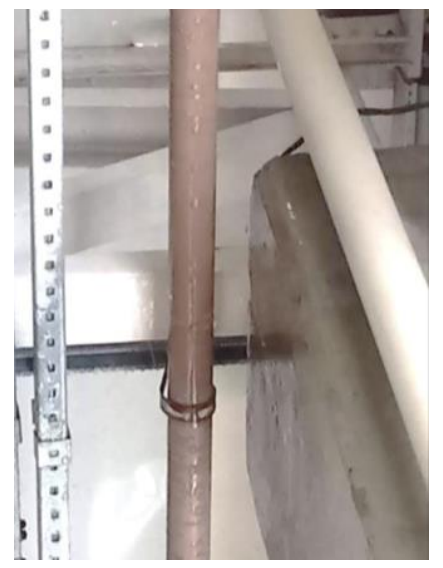

Figura 7 - Tubulação com ruptura no Shaft dos banheiros centrais

Multiplicando os valores estimados de gravidade, urgência e tendência (2, 4 e 3, respectivamente), obteve-se 24 pontos, que resulta em uma prioridade 5 (210 dia a 240 dias para sanar a manifestação). No sistema hidrossanitário, das 66 manifestações encontradas, 39\% tiveram classificação como falha de manutenção e $61 \%$ como anomalia da construção.

\subsection{Revestimentos e pinturas}

De acordo com Cincotto (1988), os defeitos mais comuns nos revestimento são as manchas, o bolor, os descolamentos, as fissuras, a desagregação e as vesículas. Esses problemas são geradores de insatisfação por parte dos usuários das edificações, destacando-se a sensação desagradável de conviver com ambientes insalubres antiestéticos (DO CARMO, 2003).

No refeitório foi verificado o descolamento do revestimento cerâmico na parede conforme (Figura 8). Presume-se que isso ocorreu devido à utilização da Argamassa Colante 1 (ACI), quando o indicado para esse tipo de assentamento é a $\mathrm{AC} 3$, que tem a capacidade de absorver as variações de temperatura, umidade e ação do vento dos revestimentos cerâmicos e de pisos. Com isso, as peças cerâmicas foram tracionadas e houve o descolamento. Para solucionar esse problema, é necessário retirar todas as peças cerâmicas e a argamassa $\mathrm{ACl}$ da parede. Em seguida, deve-se assentar novamente o revestimento com a argamassa indicada AC3. 


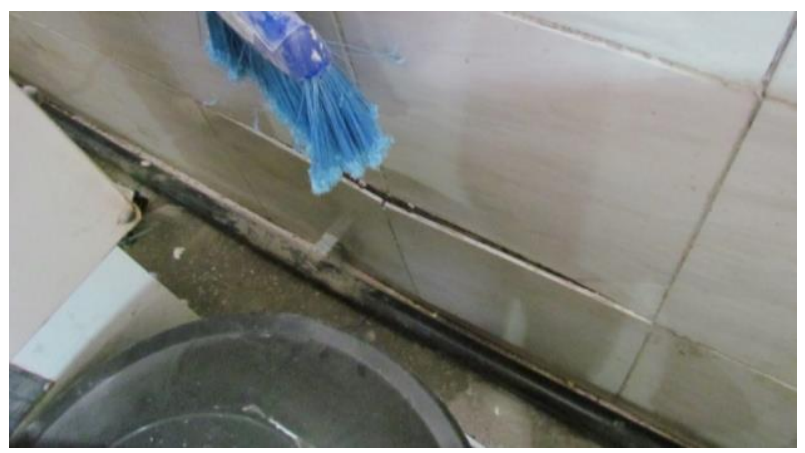

Figura 8 - Revestimento do refeitório

O descascamento da pintuta do teto apresentada na Figura 9 decorre da infiltração de água por meio do rejuntamento desgastado da sala acima. Para sanar esse problema, é necessário substituir o rejuntamento e refazer o revestimento.

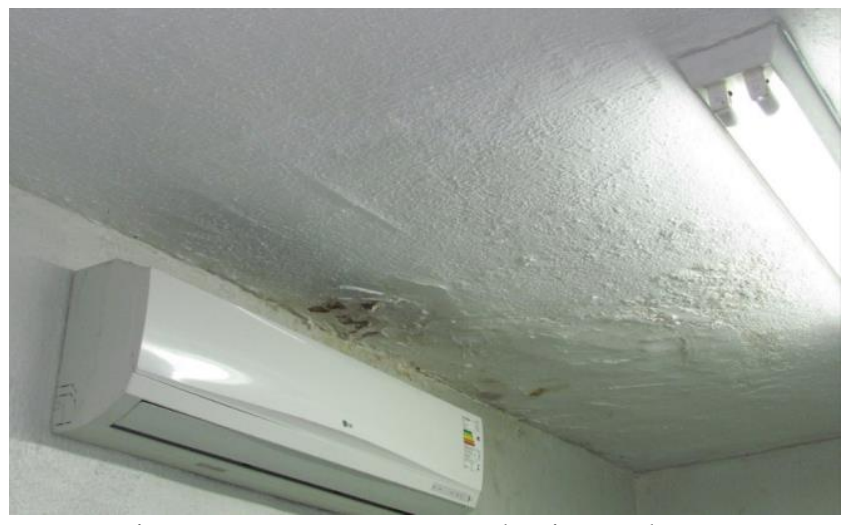

Figura 9 - Descascamento da pintuta do teto

Multiplicando os valores estimados de gravidade, urgência e tendência (2, 3 e 4, respectivamente), tem-se o resultado igual a 24 , que resulta em uma prioridade 5 (210 dias a 240 dias para sanar os problemas). Nos revestimentos cerâmicos, $85 \%$ das manifestações patológicas foram classificadas como erros durante a construção (descolamento, desnível entre peças, falta de inclinação, fissuras e manchas) e 15\% de falha na manutenção. Já nas pinturas, $41 \%$ das manifestações foram decorrentes de falha na manutenção, equanto os $59 \%$ restantes foram anomalias da construção.

\subsection{Estruturas de concreto}

Os sintomas de maior incidência nas estruturas de concreto são: ninhos de concretagem, manchas superficiais, desagregação ou degradação química, flechas excessivas, fissuras ativas e passivas, e a corrosão de armaduras.

A degradação do concreto se dá a partir de um processo interativo entre a sua massa interna e os agentes agressivos provenientes do ambiente. O concreto é um material poroso e permeável aos fluídos. A durabilidade do concreto, de acordo com Helene (2003), depende da facilidade com que os fluídos, líquidos e gasosos, ingressam no concreto e deslocam-se no seu interior

A degradação das estruturas de concreto armado tem como principal causa a corrosão das armaduras. Na Figura 10 é possível ver a ruptura da camada de concreto que envolve a armadura devido à sua expansão por corrosão. A expansão do aço oxidado pressiona a camada de cobrimento causando o desplacamento e deixando-as exposta. $\mathrm{O}$ aço exposto fica mais suscetível ao ataque de agentes que irão oxidar a armadura e diminuir sua seção resistente, comprometendo, assim, a integridade da estrutura e dos demais sistemas da edificação. 

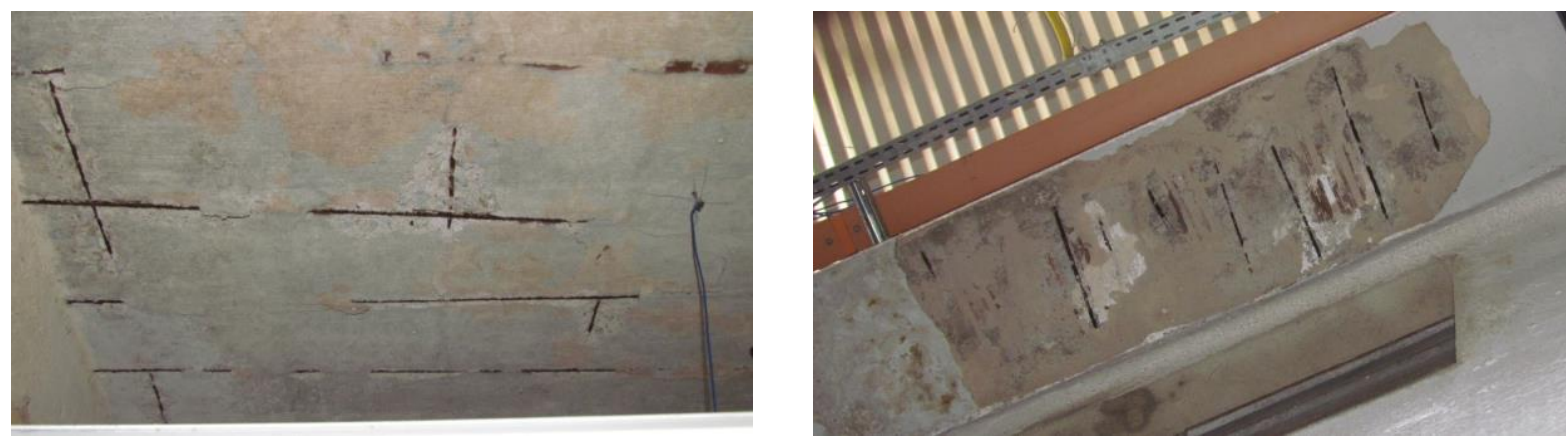

Figura 10 - Exposição das armaduras em lajes e vigas

Nesse caso, a corrosão se dá pela insuficiência da camada de cobrimento. O cobrimento protege a armadura contra os agentes externos (gases ácidos presentes no ar, por exemplo), já que, além de formar uma barreira física, promove uma proteção química por consequência do elevado $\mathrm{pH}$ do concreto que forma uma película passiva que envolve o aço.

Para esse problema, torna-se necessário avaliar o grau de comprometimento das armaduras. Em seguida, é preciso realizar uma análise estrutural para verificar se a seção efetiva é suficiente para absorver as solicitações. Caso seja, é feito um tratamento das armaduras existentes e construído um novo cobrimento de concreto. Caso seja dectada a insuficiência da armadura, será necessário projetar um reforço estrutural.

Multiplicando os valores estimados de gravidade, urgência e tendência (4, 3 e 4, respectivamente), obteve-se 48 pontos, que resulta em uma prioridade 4 (150 dias a 210 dias para sanar os problemas). Destaca-se que $100 \%$ das manifestações patológicas encontradas em estruturas de concreto foram decorrentes de anomalia na construção, seja por falha no projeto, como cobrimento mínimo, ou por falha de execução, como desagregação do concreto.

\section{CONCLUSÃO}

O presente trabalho teve como intuito indicar as principais manifestações patológicas encontradas em uma instituição de ensino superior. Com a metodologia escolhida, foi possível fazer o levantamento das manifestações patológicas existentes nos ambientes, documentar e analisar os resultados obtidos.

Os resultados indicaram que as causas das manifestações patológicas em alvenarias de vedação e estruturas de concreto foram, possivelmente, decorrentes de anomalias da construção, reforçando que não trabalhar com profissionais qualificados e habilitados traz malefícios ao longo dos anos.

Já nas pinturas, observou-se uma porcentagem de $41 \%$ de falha decorrentes de insuficiência de manutenção, confirmando a importância de ter um cronograma de manutenções periódicas para mitigar os gastos com manutenções corretivas, que são, em sua maioria, mais caras que as preventivas. A edificação visitada não possui uma empresa ou profissional habilitado encarregado da manutenção periódica das mesmas, ocorrendo apenas quando as manifestações já estão em estado aparente.

Foram mostrados, ao longo do trabalho, defeitos que ocorrem no cotidiano e que, por muitas vezes, não são tratados com a solução adequada que necessitam, tornando-os recorrentes e agravantes na grande maioria de edificações. Foi constado que $74 \%$ de manifestações patológicas decorrentes de anomalia da construção e $26 \%$ causadas por falha de manutenção.

Esse trabalho, portanto, obteve êxito nas metas propostas, uma vez que foi possível identificar as avarias cujo efeito continuado será comprovadamente danoso para adequada utilização da edificação e discutir as possíveis causas. Além disso, essa pesquisa amplia a gama de estudos de casos em que é aplicada a patologia das construções, que podem servir como base para trabalhos futuros, sejam eles acadêmicos ou profissionais.

\section{REFERÊNCIAS}

ANDRADE, T.; SILVA, A. J. C. Patologia das Estruturas. In: ISAIA, Geraldo, 2005. 
ARAÚJO, L. S. M. Avaliação durante operação dos sistemas prediais hidráulicos e sanitários em edifícios escolares. 2004. Dissertação (Mestrado) - Universidade Estadual de Campinas. Campinas, SP, Brasil, 2004.

ASSOCIAÇÃO BRASILEIRA DE NORMAS TÉCNICAS. NBR 5674. Manutenção de edificações - Requisitos para o sistema de gestão de Manutenção. Rio de Janeiro, 2012.

CAPORRINO, C. F. Patologia em alvenarias. $2^{\mathrm{a}}$ ed. São Paulo: Oficina de Textos, 2018.

CARVALHO JR, R. Patologias em sistemas prediais hidráulicossanitários. $1^{\text {a }}$ ed. São Paulo: Blucher, 2015.

CINCOTTO, M. A. Patologia das argamassas de revestimento: análise e recomendações. In: SIMPÓSIO DE DESEMPENHO DE MATERIAIS E COMPONENTES DE CONSTRUÇÃO CIVIL, 1., 1988, Florianópolis: UFSC, 1988. p. 157-170.

DAL MOLIN, D. C. C. Fissuras em estruturas de concreto armado: análise das manifestações típicas e levantamento de casos ocorridos no estado do Rio Grande do Sul. 1988. Dissertação (Mestrado) - Universidade Federal do Rio Grande do Sul. Porto Alegre, RS, Brasil, 1988.

DO CARMO, P. O. Patologia das construções. Santa Maria, Programa de atualização profissional - CREA-RS, 2003.

ELDRIDGE, H. J. Construcción, defectos comunes. Barcelona: Gustavo Gili, 1982.

GOMIDE, T. L. F.; PUJADAS, F. Z. A.; FAGUNDES NETO, J. C. P. Técnicas de Manutenção e Inspeção Predial Conceitos, Metodologias, Aspectos Práticos e Normas Comentadas. São Paulo: PINI, 2006.

GOMIDE, T. L. F.; GULLO, M. A.; FAGUNDES NETO, J. C. P. Normas Técnicas para Engenharia Diagnóstica em edificações. São Paulo: PINI, 2009.

HELENE, P. R. L. Manual de reparo, proteção e reforço de estruturas de concreto. São Paulo: Red Rehabilitar, 2003.

INSTITUTO BRASILEIRO DE AVALIAÇÕES E PERÍCIAS DE ENGENHARIA. Norma de Inspeção Predial Nacional. São Paulo. 2012. Disponível em: < http://IBAPE-nacional.com.br/biblioteca/wpcontent/uploads/2012/12/Norma-deInspe\%C3\%A7\%C3\%A3o-Predial-IBAPE-Nacional.pdf>. Acesso em: 22 out. 2018.

INTERNATIONAL ORGANIZATION FOR STANDARDZATION (ISO). General Principles on the Design of Structures for Durability. ISO 13823. Geneva: ISO/TC, 2008.

KNAPP, L.; OLIVAN, L. I. Classificação de desempenho de edificação habitacional - método GUT - estruturas metálicas. In: INSTITUTO BRASILEIRO DE AVALIAçõES E PERíCIAS (IBAPE). Proc. XVIII Congresso Brasileiro de Engenharia de Avaliações e Perícias. Belo Horizonte, 2015.

MEHTA, P. K.; MONTEIRO, P. J. M. Concreto. Microestrutura, propriedades e materiais. 3. ed. São Paulo: IBRACON, 2008.

SOUZA, V. C.; RIPPER, T. Patologia, recuperação e reforço de estruturas de concreto. $1^{\text {a }}$ ed. São Paulo: Pini, 1998.

TEIXEIRA, P.C.; REIS, R. P. A.; GNIPPER, S. F.; MONTEIRO, J. V. F. Estudo de patologia nos sistemas prediais hidráulicos e sanitários do prédio do ciclo básico II da unicamp. Revista Eletrônica de Engenharia Civil, v. 1, p. 3450, 2011.

THOMAZ, E. Trincas em edifício: Causas, prevenção e recuperação. 1ª ed. São Paulo: Pini, 1989.

VIEIRA, P. C. C. Patologias em instalações hidro-sanitárias de edifícios residenciais na zona centro-sul de Manaus (AM): diagnóstico e terapia. 2016. Dissertação (Mestrado) - Universidade Federal do Pará. Belém, PA, Brasil, 2016. 